\title{
Discussion on the Construction Mode Change of Literature Resources of Library Based on Big Data Environment
}

\author{
Zhenwei Wang \\ Library, Guangdong University of Science and Technology, Dongguan 523083, China
}

Keywords: Big Data; Library; Literature resources; Construction models; Change

\begin{abstract}
In the current development of big data, the literature resources of library is analyzed starting with the characteristics of big data, and then the basic model of the literature resources construction of library is found out to strive to improve the quality of library services better and change the previous single service approach, so that big data can be shared and provide readers with more reference.

With the advent of the era of big data, everyone's thinking needs to change, and under the circumstances of big data, comprehensive construction and analysis of the literature resources are carried out to grasp the opportunity of era development and improve the quality of library work in the process of change.
\end{abstract}

\section{Basic Features of the Big Data Era}

With the rapid development of network information, the era of big data has come. A large amount of data information has become a new type of weapon for enterprise development. Every enterprise or every field is trying to find out more data to support its own development. Big data provides suggestions and opinions for corporate decision-making and provides more data guidance. This is a new way of thinking. More detailed data base is used to support real-world data analysis, to some extent, reducing the benefit risk of companies. In recent years, big data has appeared in every field of our country like mad, and now it has entered the data sharing stage. In this stage, the characteristics of big data mainly include the following aspects.

First of all, the amount of data is huge, and the amount of data generated every hour in each site has already reached 300TB, for example, Facebook, which is widely known by people.

Secondly, big data is diverse. The information resources provided by big data are various, and they can be divided into categories and provide services in multiple areas.

In the end, the value of big data is very high. Many data are contained in big data systems, and most of them are some very important frontier information studied and explored by experts, medical researchers constantly. Most of the data are more theoretical and scientific, and can be shared by multiple people through the information platform. This will virtually increase the intrinsic value of the data.

In addition, the flow of big data is very fast. In the current era of big data, the soaring and development of science and technology has greatly advanced the progress of social spiritual civilization. For big data, it also shows a dynamically changing form from the beginning, and each type of data is also in a state of continuous development. The old data is soon replaced by new data.

\section{Composition and Value of Library Literature Resources in the Era of Big Data}

\section{Analysis of Library Literature Resources Composition in the Era of Big Data}

There are many kinds of big data resources in the library, including readership data, readers' various types of literatures, application data, and so on. In the long-term development process, the principle of the library development has always been to provide the best quality service for readers. Businesses are also part of the library. In the current development process, it is seen as an object of the library to enhance self-management and service quality. In short, if the library lacks the corresponding literature resources, then it will lose the fertile ground and the foundation to serve the readers and develop. From the aspect of system composition, library literature resources mainly 
include three aspects in the construction process, namely self-built literature resources, commercial literature resources and construction document resources. The construction mode of self-built literature resources needs a lot of manpower and material resources, and requires a lot of funds to support. Therefore, under normal circumstances, it mainly supports the construction of some very special and high-value documents in the library. The construction of commercial documentary resources is relatively susceptible to a variety of factors, where the most influential factor is the acquisition cost, so that the amount of construction is significantly reduced. Many of the construction documents are supported by free literature with obvious academic characteristics. This is also a new initiative of the library for readers and has been welcomed by most readers. The types of document resources developed in domestic libraries are abundant and therefore, for libraries, they also need to be well prepared for funding to strive for a big expansion of literature resources.

\section{Analysis of the Value of Library Literature Resources in the Era of Big Data}

The application of literature resources has played an important role in various fields. For example, scientific research or education, research and analysis, etc. all require the use of literature resource data. To a certain extent, the use of literature resource data has played a very important role in scientific research achievements. Thus, the construction of library documentation resource data needs to be done to some extent. It contains the construction and updating of database. In the current development process, many domestic library organizations have established a library of relevant literature data and collected and screened as well as verified relevant data well in order to meet the different literature needs of readers. The data is arranged firstly and then stored, so that the data faced to the reader has higher value and facilitates the use of readers, playing a more active role in the service.

\section{The Change of Literature Resources Construction Mode of Library in Big Data Environment}

\section{Improve the Literacy of Librarians in The Background of Big Data}

The era of big data has come. Faced with different types of databases and different data structures, library managers are required to learn more. For the heterogeneous data, they need to be unified and integrated and taken relevant measures for further processing, which make the data more reliable and secure. Relevant professional data personnel can analyze the data for further prediction, which greatly enhances the value of data use. Then as library managers, they also need to have such comprehensive qualities in order to solve the above problems. In the process of library upgrade management, learning of some related introduced advanced data software has become a new professional skill for management personnel. The software contains a variety of knowledge maps, which become the most popular and identified maps. Only continuous learning and improvement will enable us to master more. Only professional knowledge can manage the library and provide readers with accurate services in the era of big data.

\section{Establishing the Big Data Thinking of Literature Resources}

In the current state of continuous development of big data, each area has uses big data a lot, and from the beginning of random uses to the present more comprehensive uses. Compared with the traditional data of the past, the data in the era of big data is more diverse and mixed, which may have certain flaws in the accuracy. Especially for the algorithm of big data, compared with the algorithm of small data, it shows some complex features and the effect is obvious. In the process of development in the past two years, a relatively tight and mutually exclusive relationship has also emerged between big data and small data. If it's analyzed from the perspective of library work and service, every library staff needs to establish big data thinking. For different users, they also need to be treated with an equal attitude. We must strive to be able to provide users with more services and help from operating and actually.

\section{Use Big Data to Accurately Push Documents}

In the context of big data, alternative metrology is created. This is a kind of evaluation method that has been developed on the social network and has great influence. It can improve the use of academic social networks through the acquisition of multiple data. In the process of document management, a certain achievement is studied, calculated, and the relevant data information is 
known, and then the degree of attention of the network is increased after measurement and research. This can also use data comprehensively and directly to reflect the situation of library management, the influence of libraries and so on. There are resources related to OA in library collections, so people have a certain level of attention and elevation on this resource. Most libraries still lack related OA resources or corresponding reference tools, so alternative metrology in libraries has played a greater role and has also collected more resources as a tool.

\section{Using Big Data to Implement Document Resources Automation Management}

There are some humanities subjects in the library collection process, and they also occupy most of the library space. However, due to a variety of factors, the quality of these books in the library is arbitrary, and there are serious shortages in the collections, which affect the borrowing of books, and therefore there is a need to increase the amount of borrowing. Under normal circumstances, mainstream libraries do not pay much attention to users' information collection. They only pay attention to the type and composition of books and lack the services to provide users with decision-making advice. However, for the Huiwen system updating under the background of big data, it has a large amount of data collection, which can make users more assisted in the process of selecting books.

\section{Conclusion}

In conclusion, the change of literature resource construction model of library is analyzed and studied under the big data environment. In the big data environment, the library begins to update service methods continuously. Big data has its own characteristics and values. The change of library in the new period also needs to be analyzed from the aspect of upgrading the basic qualities and professional capabilities of the personnel. In addition, it is necessary to establish the thinking of data resources, use modern systems to solve many problems in the library, and improve service quality.

\section{References}

[1]Li Yang.Analysis of the Construction of the Library Information Resources from the Perspective of Big Data[C].//Information technology applications in industry III: Selected, peer reviewed papers from the 2014 3rd International Conference on Information Technology and Management Innovation (ICITMI 2014), July 19-20, 2014, Shenzhen, China.2014:1047-1050.

[2]Jordanous, Anna.Enhancing information retrieval and resource discovery from data using the Semantic Web[C].//2015 4th International Symposium on Emerging Trends and Technologies in Libraries and Information Services: 2015 4th International Symposium on Emerging Trends and Technologies in Libraries and Information Services (ETTLIS), 6-8 January 2015, Noida, India.2015:105-110.

[3]STEVEN OVADIA.The Role of Big Data in the Social Sciences[J].Behavioral \&amp;amp; social sciences librarian,2013,32(2):130-134.

[4]Thessen, A.E.,Cui, H.,Mozzherin, D. et al.Applications of natural language processing in biodiversity science (Review)[J].Advances in Bioinformatics,2016,2012:391574-1-391574-17. 